\title{
A cost-efficiency and health benefit approach to improve urban air quality
}

\author{
A.I. Miranda a , J. Ferreira a,*, C. Silveira ${ }^{a}$, H. Relvas ${ }^{a}$, L. Duque a , P. Roebeling a , M. Lopes ${ }^{\text {a }}$, S. Costa ${ }^{\text {b,c }}$, \\ A. Monteiro ${ }^{a}$, C. Gama ${ }^{\text {a }}$, E. Sá ${ }^{\text {a }}$, C. Borrego ${ }^{\text {a }}$, J.P. Teixeira ${ }^{\text {b,c }}$ \\ ${ }^{a}$ CESAM E Department of Environment and Planning, University of Aveiro, 3810-193 Aveiro, Portugal \\ ${ }^{\mathrm{b}}$ EPIUnit-Institute of Public Health, University of Porto, Porto, Portugal

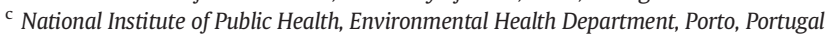

\section{H I G H L I G H T S}

- 4 abatement measures to reduce PM10 and NOx emissions characterized in terms of emissions and implementation costs

- Air quality and health impacts quantified by air quality modelling, cost-efficiency analysis and health impact functions

- The resulting scenario including all 4 measures lead to a total net benefit of $0.3 \mathrm{M} € \cdot \mathrm{y}^{-1}$

- MAPLIA system is a useful tool for policy decision support for air quality improvement

\section{G R A P H I C A L A B S T R A C T}

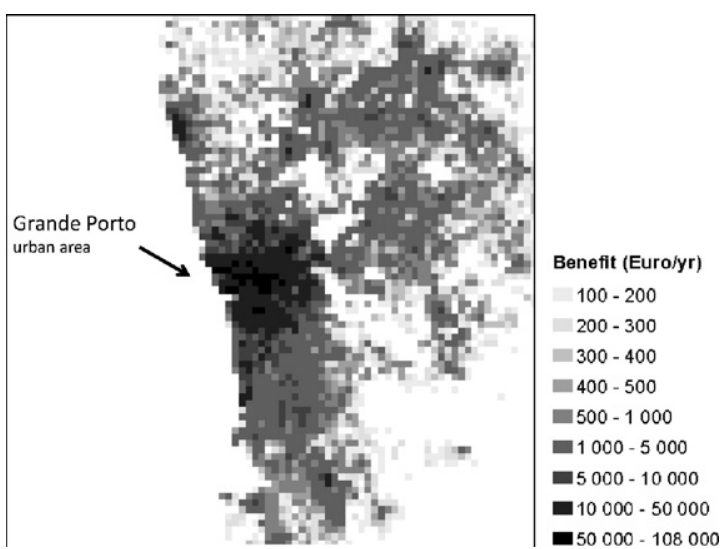

An integrated assessment modelling system was applied to an urban area to assess the impacts of emission abatement measures, for PM10 and $\mathrm{NO}_{2}$, on air quality and human health by means of a cost-benefit analysis. The largest contribution for health benefits derives from the reduction in PM10 concentrations in the Grande Porto municipalities.

\section{A B S T R A C T}

When ambient air quality standards established in the EU Directive 2008/50/EC are exceeded, Member States are obliged to develop and implement Air Quality Plans (AQP) to improve air quality and health. Notwithstanding the achievements in emission reductions and air quality improvement, additional efforts need to be undertaken to improve air quality in a sustainable way - i.e. through a cost-efficiency approach. This work was developed in the scope of the recently concluded MAPLIA project "Moving from Air Pollution to Local Integrated Assessment", and focuses on the definition and assessment of emission abatement measures and their associated costs, air quality and health impacts and benefits by means of air quality modelling tools, health impact functions and cost-efficiency analysis. The MAPLIA system was applied to the Grande Porto urban area (Portugal), addressing PM10 and NOx as the most important pollutants in the region. Four different measures to reduce PM10 and NOx emissions were defined and characterized in terms of emissions and implementation costs, and combined into 15 emission scenarios, simulated by the TAPM air quality modelling tool. Air pollutant concentration fields were then used to estimate health benefits in terms of avoided costs (external costs), using dose-response health impact functions. Results revealed that, among the 15 scenarios analysed, the scenario including all 4 measures

\footnotetext{
* Corresponding author.

E-mail address: jferreira@ua.pt (J. Ferreira).
} 
lead to a total net benefit of $0.3 \mathrm{M} € \cdot \mathrm{y}^{-1}$. The largest net benefit is obtained for the scenario considering the conversion of $50 \%$ of open fire places into heat recovery wood stoves. Although the implementation costs of this measure are high, the benefits outweigh the costs. Research outcomes confirm that the MAPLIA system is useful for policy decision support on air quality improvement strategies, and could be applied to other urban areas where $\mathrm{AQP}$ need to be implemented and monitored.

(c) 2016 Published by Elsevier B.V.

\section{Introduction}

Nowadays, poor air quality is recognized as one of the most pressing problems in urban areas with very harmful impacts on health and the environment (EEA, 2015). Moreover, the World Health Organization (WHO) has recently classified air pollution as carcinogenic to human beings (WHO, 2013a). According to the latest report on air quality in Europe (EEA, 2015), air pollution implications are mainly due to high levels of particulate matter (PM) and ozone $\left(\mathrm{O}_{3}\right)$ in the atmosphere. Anthropogenic emissions are identified as the greatest contributors to air pollutant concentrations, but atmospheric phenomena occurring at different spatial scales also contribute to the increase in environmental damages.

In order to reduce air pollution effects, particularly in cities where the majority of the European population lives, it is important to define effective plans for air quality improvement. For this purpose, Air Quality Plans (AQP) establishing emission abatement measures, previously known as Plans and Programmes, have to be designed and implemented by the Member States (MS) of the European Union (EU) in accordance to the Framework Directive 96/62/EC on ambient air quality assessment and management, whenever in their zones and agglomerations the pollutant concentrations in ambient air exceed the relevant air quality limit values. In 2008, based on the Framework Directive and in other previously existing legal documents, a new Air Quality Directive (AQD) (Directive 2008/50/EC) was published, introducing new concepts, and simplified and reorganized guidelines. The application of numerical models is highlighted in this new Directive as a fundamental tool to better assess and manage air quality, encouraging their use in the preparation of AQP. These models must be used in combination with monitoring in a range of applications, as observed values are crucial for validation of these modelling approaches.

In most European MS the modelling tools used in AQP consider processes directly influencing air quality, from the emission to dispersion and deposition of air pollutants, but do not include, for example, exposure or indicators related to health (Miranda et al., 2015). Together with air quality assessment, quantifying the impact of air pollution on the public's health is a critical component for the design and evaluation of effective local and regional AQP (Costa et al., 2014), although not directly required by legislation. Indeed, several scientific findings show that current levels of air pollutants observed in European cities are associated with health risks, such as, cardiovascular diseases and lung cancer (Brook et al., 2004; Loomis et al., 2013; WHO, 2013a). Health impact assessments provide an objective estimate of the influence of mitigation measures on air quality and population health. It uses available epidemiological studies together with routine environmental and health data to evaluate the potential effects of a policy, programme or project on the health of a population, including how those effects are distributed across the population - thus helping decision makers to plan and implement measures to protect public health more effectively. When economic values are applied to these health endpoints, the monetary costs and benefits of different options can also be compared directly (O'Connell and Hurley, 2009).

The risk of developing a disease due to exposure to agents with different levels of intensity and duration can be assessed using a statistical model and corresponding exposure-response functions (ERF) (Smith et al., 1999). In the case of AQ an ERF links the concentration of pollutants to which a population is exposed with the number of health events occurring in that population. They may be reported as a relative risk of a certain health response for a given change in exposure or as a slope from a linear regression model between the exposure and the risk of a certain health response. It should be noted that health effects can occur within a short period after exposure (short-term exposure) resulting in acute effects, or as a cumulative exposure over a longer period of time (long-term exposure) expressed as chronic effects. The appropriate selection of adverse health outcomes and ERFs is a critical step. The findings of epidemiological studies provide the scientific basis for these decisions. Thus, the impact is determined by the relation of two variables: exposure and effect. One or more indicators are used to express the change in population health status due to exposure to an air pollutant (stressor); most health-based indicators are or derive from mortality and morbidity endpoints.

Regarding the health impacts arising from air pollution, the following aspects in epidemiological studies are considered: (i) involved pollutants and their air concentration levels; (ii) health indicators analysed in terms of morbidity and mortality; (iii) affected age groups; and (iv) exposure time. These data are used to quantify the extent of these impacts evaluated through ERF and health outcome frequencies which, combined with the population exposure to air pollution changes after the implementation of air quality improvement measures, provides the number of attributable cases/days per health indicator (Eq. (1)) (EC, 2005).

$\Delta \mathrm{R}_{\mathrm{i}}=\mathrm{I}_{\mathrm{ref}} \times \mathrm{CRF}_{\mathrm{i}, \mathrm{p}} \times \Delta \mathrm{C}_{\mathrm{p}} \times \mathrm{pop}$

where:

$\Delta R_{i}-$ Response as a function of the number of unfavourable implications (cases, days or episodes) over all health indicators $(i=1, \ldots, \mathrm{n})$ avoided or not;

$\mathrm{I}_{\mathrm{ref}}$ - Baseline morbidity/mortality annual rate (\%);

$\mathrm{CRF}_{\mathrm{i}, \mathrm{p}}$ - Correlation coefficient between the pollutant p's concentration variation and the probability of experiencing or avoiding a specific health indicator $\mathrm{i}$ (\%, i.e. Relative Risk RR associated to a concentration change of $1 \mu \mathrm{g} \cdot \mathrm{m}^{-3}$ );

$\Delta ;$ p - Change in the pollutant p's concentration $\left(\mu \mathrm{g} \cdot \mathrm{m}^{-3}\right)$ after the adoption of abatement measures (emission scenarios); and

pop - Population units per age group exposed to pollutant $\mathrm{p}$.

ERF values are usually derived from epidemiological studies due to absence of specific information on exposure-response relationships for the target area/population under study. Therefore, it is recommend selecting reference and up-to-date ERF preferably from an authoritative and influential institute or organisation (INTARESE, 2007). Usually the ERF used to calculate the response to pollutants exposure in Europe are from well-known USA studies (e.g. Harvard Six Cities study). However European cohort studies have also shown results consistent with a causal link between long-term air pollution exposure and mortality in Europe (Gehring et al., 2006; Raaschou-Nielsen et al., 2013). WHO has recently published a set of recommendations for ERF and cost-benefit analysis of key pollutants in support of the European Union's air quality policy revision (WHO, 2013b), where ERF and related background information for several mortality and morbidity effects associated with short and long-term exposure to particular air pollutants, such as particulate matter $(\mathrm{PM})$, ozone $\left(\mathrm{O}_{3}\right)$ and nitrogen dioxide $\left(\mathrm{NO}_{2}\right)$, are provided.

Health impacts need to be translated into monetary values (i.e. external costs), in order to be properly considered as economic costs. 
These external costs are generally divided into three broad categories: direct costs (health care costs), indirect costs (productivity and production losses) and intangible costs (pain and suffering). Direct and indirect costs are estimated on the basis of market prices, while intangible costs are based on non-market prices (Pervin et al., 2008).

Methodologies combining the effects of several emission abatement measures on the air quality and potential impacts on human health, as well as the economic evaluation associated to the implementation of measures and resulting external costs, enable cost-benefit/efficiency analyses of the control options (Amann et al., 2011) and are an added value to the decision-making process. For this reason, in the recent years, Integrated Assessment Methodologies (IAM) for air quality planning (encompassing health impact assessment) have already been formulated and implemented at the continental and national scales (e.g. Comes et al., 2010; Karvosenoja et al., 2010; Vedrenne et al., 2014). In the scope of the FP7 APPRAISAL Project, an overall review has been performed concerning IAM used in different MS to evaluate the impact of local and regional air quality plans and their health implications (APPRAISAL, 2013a). With few exceptions (e.g. Mediavilla-Sahagún and ApSimon, 2006; Mensink et al., 2003; Vlachokostas et al., 2009; Zachary et al., 2011; Carnevale et al., 2012), IAM on a regional and local scale are scarce. This lack of local IAM arises from the difficulty to fully characterize, with enough spatial detail, the "within country" variability in emission patterns due to, for example, socio-economic characteristics, geographical variations in urbanization, and particular meteorological and chemical conditions. Integrated assessment in terms of local air quality compliance must, therefore, be a bottom-up approach that links decision making, air quality dynamics (often nonlinear), source identification and consequent health impacts in a customised but consistent way to suit the capability and needs of each regional/local situation (APPRAISAL, 2013b).

This work is focused on the definition of emission abatement measures and the assessment of their associated costs, air quality and health impacts and benefits by means of air quality modelling tools and costefficiency analysis and health impact functions, specifically developed for urban areas in the scope of the recently concluded MAPLIA project "Moving from Air Pollution to Local Integrated Assessment".

\section{The MAPLIA system}

The MAPLIA system was designed to support the development of $A Q P$ requiring the definition and testing of specific and local/regional abatement measures. It is based on a scenario analysis, which starts with the identification of control strategies/measures as a result of air quality exceedances. These measures have to be translated into emission reductions and their impacts on air quality quantified using modelling tools. Policy implications, technical feasibility, resulting costs and health impacts are evaluated, but not in a fully integrated perspective.

The MAPLIA system allows, therefore, evaluating the effects of previously selected measures in terms of costs, emissions, air quality, health impacts, and associated monetary benefits (also called avoided external costs). For this purpose, scenarios including different emission abatement measures are defined and their implementation costs are estimated. A reference scenario reflecting the emissions of a base year, for which only the influence of imposed/implemented measures in accordance with the legal framework is evaluated (CLE - Current Legislation Emissions), is the basis for the assessment. Reduction scenarios are established to cover non-compliance situations to the air quality limit values defined in the air quality Directive (2008/50/EC), aiming to act in an efficient and incisive way on the major emission sources in order to achieve significant benefits as compared to the reference scenario. The flowchart of Fig. 1 presents the different stages considered in the MAPLIA system.

The first steps of the flowchart consist in the definition of scenarios the reference scenario and a set of reduction scenarios which are represented by emission reduction measures addressed to one or more

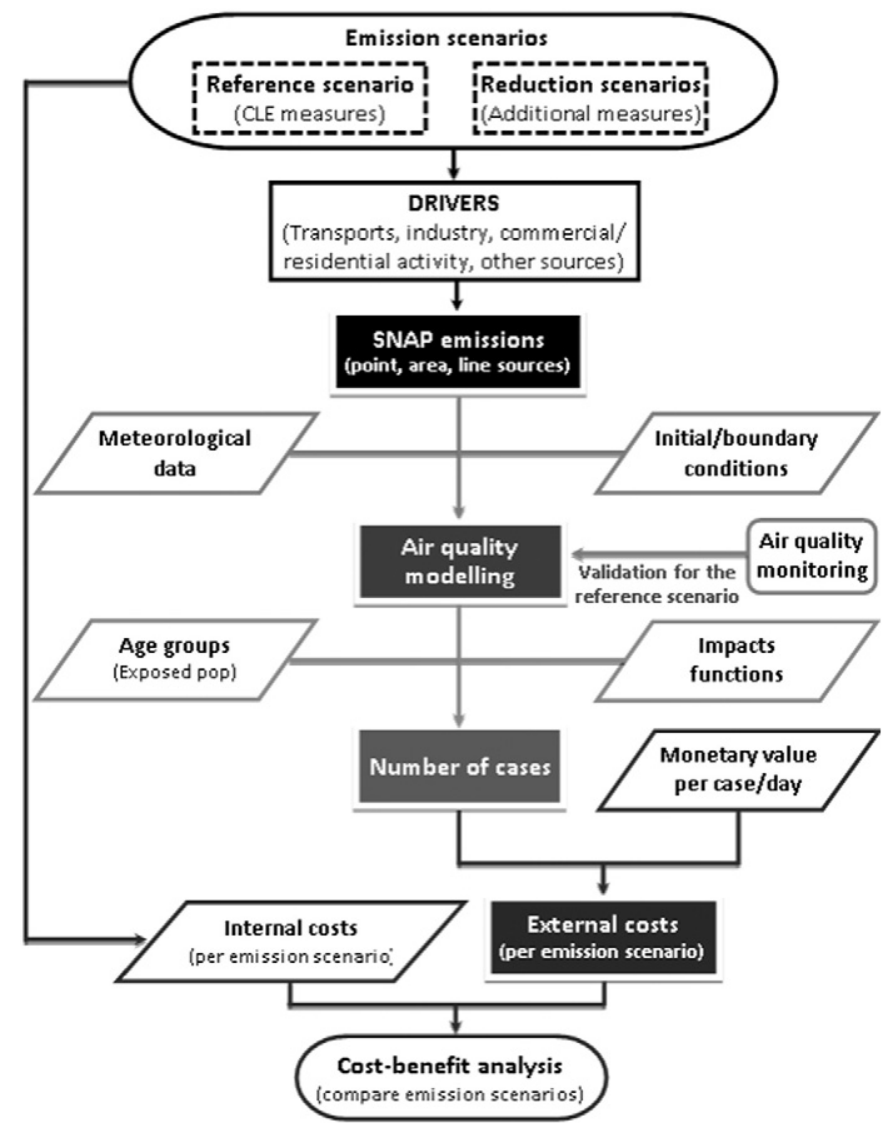

Fig. 1. Methodological flowchart of the MAPLIA system (SNAP, Selected Nomenclature for sources of Air Pollution, refers to the emission source categories considered).

drivers. Based on the defined emission reduction scenarios, resulting emissions and air quality have to be quantified. For each reduction scenario the emissions by activity sector directly connected to the respective driver(s) are estimated. The next step aims to determine the effect of each emission reduction scenario on air quality by means of air quality modelling. Apart from emissions, meteorological data and initial and boundary conditions are required for the modelling application. The following steps (number of cases, external and internal costs) end up in the cost-benefit analysis. The concentration values estimated by an air quality model, jointly with population data and morbidity and mortality indicators (expressed as health impact functions), allow calculating the number of attributable cases/days according to Eq. (1). The number of cases is then translated into monetary values allowing for the estimation of the avoided external costs (or health benefits) per emission reduction scenario. These costs are compared with the internal/implementation costs of the respective scenario to identify the most cost-efficient policies for air quality management. The latter cost-benefit analysis has a clear added value in the decision-making process.

The MAPLIA system offers a methodology that can be applied to different study areas through the preparation of a set of input information, namely: a detailed emission inventory, emission reduction scenarios, reduction measures and related costs, population distribution by age, health indicators, and source-receptor links. The objective and main goal of the MAPLIA system is the use of specific local data to assure that outputs meet the specific needs of stakeholders and policy makers in the region and provide effective support in the decision making process at the local scale. 


\section{Application to a case study}

The Grande Porto area (11 municipalities) was selected for the application of the MAPLIA system for the reference year 2012. It covers a total area of $1024 \mathrm{~km}^{2}$ with a total population of $>1.2$ million inhabitants. This region of Portugal is one of several EU zones that had to develop and implement air quality plans (AQP) to reduce PM10 and $\mathrm{NO}_{2}$ concentrations (Borrego et al., 2012a, 2012b; Miranda et al., 2015). This case study was selected based on the registered exceedances to the air quality limit values and on the available AQP to be used as a basis for further policy support.

\subsection{Emission abatement measures and internal costs}

The most updated national emission inventory report (APA, 2014), for the year 2012, was used to develop the reference emissions case. The annual emissions data were disaggregated by municipality and allocated to SNAP categories: commercial and residential combustion (SNAP02); industrial combustion (SNAP03); production processes (SNAP04); extraction and distribution of fossil fuels and geothermal energy (SNAP05); solvent and other product use (SNAP06); road transport (SNAP07); other mobile sources and machinery (SNAP08); waste treatment and disposal (SNAP09). Measures required to reduce PM10 and $\mathrm{NO}_{2}$ concentrations were investigated and selected for further assessment. In this sense, the criteria used for the selection included: (i) relative contributions of each activity sector to the total pollutant emissions; (ii) types of exceedances (annual/daily) and the monitoring sites where they were registered; (iii) actions already included in the defined and implemented AQP. According to the national emission inventory, the share of NOx and PM10 emissions per activity sector for the Grande Porto area identifies industrial combustion, residential combustion and road traffic as the most relevant emission sectors. Following those criteria, and knowing that the monitoring sites with higher concentrations are located in urban and traffic sites, four abatement measures were defined (more details can be found in Duque et al., 2016):

- Replacement of $10 \%$ of vehicles below the EURO3 class (diesel and gasoline) by hybrid vehicles (HYB);

- Introduction of a Low Emission Zone (LEZ) for a specific area in Porto, restricted for vehicles below EURO3 (LEZ);

- Replacement/reconversion of 50\% of the conventional fireplaces by more efficient equipment (residential combustion) (FIR);

- Application of clean technologies that allow a reduction of $10 \%$ in PM10 emissions from production processes and industrial combustion (IND).

Each one of these local emission abatement measures was characterized in terms of application rate, reduction efficiency, and implementation costs. The internal/implementation costs of the reduction measures were calculated on an annual basis, taking into account the initial investment for replacement/acquisition and installation of the new equipment or technology, as well as the operating costs including the repair and maintenance costs, based on the average lifespan of the equipment.

A total of 30,740 vehicles are involved in the measure considering the replacement of $10 \%$ of the oldest vehicles (previous to EURO3 standards; EURO1 and EURO2) by hybrid cars which are powered by both an internal combustion engine and an electric motor, and emit, on average, less pollutants than the conventional diesel/petrol cars (Soret et al., 2014). To simulate the emissions related to this measure, the reference vehicle fleet for the Grande Porto area was changed, and the TREM model (Transport Emission Model for Line Sources) (Borrego et al., 2004, 2006) was run for the new share of EURO1 + EURO2 vs hybrid. Reference traffic emissions estimated using TREM were based on Origin/Destination matrices, traffic counts available for the Porto urban area, average vehicle speed in each main arterial, and statistical data on the vehicle fleet for Porto. The application of this measure resulted in a 15\% reduction in PM10 emissions, 5\% in NOx emissions and 1\% in volatile organic compounds (VOC). This measure considers an additional investment cost (compared to non-hybrid vehicles) of $2945 € \cdot$ vehicle $^{-1}$, reduced running costs (compared to non-hybrid vehicles) of $163 € \cdot$ vehicle $^{-1} \cdot \mathrm{y}^{-1}$ and an expected lifetime of 15 years.

The Low-Emission Zone (LEZ) defined in this study covers an area of about $1.5 \mathrm{~km}^{2}$ in Porto with high traffic density, where one of the air quality monitoring sites with $\mathrm{NO}_{2}$ and PM10 exceedances is located. The considered measure implied that only vehicles above EURO3 were allowed to circulate through this restricted area. The application of this measure resulted in a reduction in PM10 and $\mathrm{NO}_{2}$ emissions of, respectively, 0.4 and 10.8 ton per year. The LEZ measure entails monetary charges with the installation of new signage $\left(17.3 \mathrm{k} € \cdot \mathrm{km}^{-2}\right.$ and a lifetime of 25 years) and operationalization of surveillance $(24.6 \mathrm{k}$ $€ \cdot \mathrm{km}^{-2} \cdot \mathrm{y}^{-1}$ ) (based on CCDR-LVT, 2006).

Residential combustion is a major contributor to the total PM10 emissions in Portugal, and in the Porto urban area in particular (APA, 2014; Borrego et al., 2010). According to studies conducted by the United States Environmental Protection Agency (USEPA, 2009), replacing traditional fireplaces by certified wood burning appliances can result in a reduction of over $80 \%$ in PM emissions. In this context, the scenario considers the replacement of $50 \%$ of the traditional fireplaces by more efficient equipments (such as heat recovery systems). Taking into account the fuel (wood) consumption per district (Gonçalves et al., 2012), the type of residential combustion equipment per sub-municipality (INE, 2012), emission factors used by the Portuguese Agency for the Environment (APA, 2014), and considering that the reconversion/ replacement of a conventional fireplace allows for a reduction of 70\% in PM10 emissions (GAINS database: http://gains.iiasa.ac.at/models), a maximum reduction of $35 \%$ per square kilometre of PM10 emissions allocated to the SNAP2 (residential combustion) was obtained. The measure FIR entails 17,543 units with an investment cost (replacement) of $840 € \cdot$ unit $^{-1}$ and an expected lifetime of 25 years.

Industrial combustion (SNAP3) and production processes (SNAP4) are also important sources of total PM10 emissions, as reported by the Portuguese emission inventory (APA, 2014). The emission reduction associated to this measure was calculated under the assumption that PM10 emissions are reduced by 10\% using new high-efficient clean technologies in both macro-sectors, including de-dusters (e.g. cyclones and electrostatic precipitators) as well as good practices in industrial processes-storage and handling, leak detection and repair programs. Based on the removal efficiencies and implementation costs of these technologies (obtained from the GAINS database for Portugal; IIASA: http://www.iiasa.ac.at), corresponding annual implementation costs were determined and weighted for the study domain taking as a basis the GAINS projections for economic development in Portugal.

\subsection{Air quality impacts and external costs (benefits)}

The above described abatement measures were selected and tested individually and in combination, totalling 15 reduction scenarios. The MAPLIA system was applied to each one of these scenarios.

The model selected to perform the air quality simulation over the study region was "The Air Pollution Model" (TAPM) (Hurley et al., 2005), developed by the Australia's Commonwealth Scientific and Industrial Research Organisation (CSIRO). This model is a 3-D Eulerian model, composed of two modules which predict meteorology and air pollution concentrations based on fundamental fluid dynamics and scalar transport equations. Technical details of the model equations, physical and chemical parameterisations, as well as its numerical methods, are described in Hurley et al. (2005). This modelling system has already been extensively applied over Portugal and the Porto region, exhibiting good agreement when compared/validated against observational data (Borrego et al., 2012a, 2012b; Duque et al., 2016). 
TAPM was run on chemistry mode with sulphur and fine particle chemistry. The gas-phase is based on a semi-empirical mechanism entitled the Generic Reaction Set (GRS), including 10 reactions for 13 species. To simulate the air quality, for the year 2012, TAPM has been setup on three nested domains with a horizontal resolution of 10, 3 and $1 \mathrm{~km}$ side-length centred on Iberian Peninsula, Northern and Central Regions of Portugal, and the Porto urban area, respectively. The Porto urban area inner domain covers an area of $80 \mathrm{~km} \times 80 \mathrm{~km}$. Background concentrations were used by the model to initialize pollutant concentrations and were also used as inflow boundary conditions on the outer grid. These background concentrations were obtained estimating the annual average of the background air quality values measured by the monitoring sites in the study region, during 2012.

The annual emission data for each pollutant and activity sector was spatially and temporally disaggregated using a top-down approach (Monteiro et al., 2007) in order to obtain the required resolution for the selected simulation domain. SNAP01 (energy production) emission sources and the larger sources of SNAP03 and 04 were considered as point sources, amounting to a total of 8 point sources within the modelling domain. For the SNAPO2 emissions (from residential combustion) activity data were obtained based on regional activity data disaggregated at sub-municipality level and taking into account the number of households with heating systems, which were characterized in terms of equipment type and fuel used. The amount of fuel consumed and emission factors per residential combustion device were used for the emission calculation. More details can be found in Duque et al. (2016). Road transport emissions (SNAP07) were spatially disaggregated through the top-down approach, but main roads in the urban area of Porto and motorways were considered as line sources. These line source emissions were estimated using the TREM model, based on available traffic counts and statistical data of the fleet composition. The TAPM model simulations included the reference and reduction scenarios.

The human health impacts derived from the achieved air quality state for the different reduction scenarios, considering a $1 \mathrm{~km}^{2}$ spatial resolution simulation grid, were quantified using Eq. (1). These health impacts were analysed through morbidity and mortality indicators associated with air concentrations of PM10 and $\mathrm{NO}_{2}$ due to short and long-term exposure. The information included in Fig. 2 and population data by age group (extracted from the National Statistical Institute database; Census 2011) at the subsection level, were used. The number of cases and the annual costs per health indicator allowed calculating avoided costs (health benefits) per reduction scenario. For each health indicator, values were expressed as annual average costs (Pervin et al., 2008), taking into account the duration and chronic effects of the disease (Fig. 2).

Figs. 3 and 4 present the spatial distribution of annual concentration averages $\left(\mu \mathrm{g} \cdot \mathrm{m}^{-3}\right)$ obtained for the reference case and for the scenario considering all emission reduction measures (in terms of percentage) and the human health benefits or avoided external costs $\left(€ \cdot y^{-1}\right)$ for this total reduction scenario, for PM10 and $\mathrm{NO}_{2}$, respectively.

Model simulation results for the reference scenario show higher annual averages for both pollutants ([PM10] $>30 \mu \mathrm{g} \cdot \mathrm{m}^{-3}$ and $\left[\mathrm{NO}_{2}\right]>25 \mu \mathrm{g} \cdot \mathrm{m}^{-3}$ ) over Porto and the surrounding area mainly, where concentrations exceeding the legislated limit values are expected (see the first map of Figs. 3 and 4). The remaining domain is characterized by low annual concentrations ([PM10] $\cong 15-20 \mu \mathrm{g} \cdot \mathrm{m}^{-3}$ and $\left[\mathrm{NO}_{2}\right] \cong 10 \mu \mathrm{g} \cdot \mathrm{m}^{-3}$ ). According to Duque et al. (2016), the comparison with observed values indicated that TAPM over-predicts PM10 concentrations in the urban area and under-predicts $\mathrm{NO}_{2}$.

The largest reductions in PM10 annual concentration are obtained for the application of FIR and IND measures and a combination of them (Duque et al., 2016). Regarding $\mathrm{NO}_{2}$, the HYB measure is the one that contributes most to the reduction in $\mathrm{NO}_{2}$ annual concentrations over the study region. The combination of all referred measures (HYB + FIR + LEZ + IND) leads to a reduction of $4.5 \%$ at most for PM10 and $\mathrm{NO}_{2}$ pollutant concentrations - mainly over Porto for PM10 and extended across the entire study region for $\mathrm{NO}_{2}$. This corresponds to reductions of up to $2.8 \mu \mathrm{g} \cdot \mathrm{m}^{-3}$ for PM10 and up to $1.2 \mu \mathrm{g} \cdot \mathrm{m}^{-3}$ for $\mathrm{NO}_{2}$.

The spatial pattern of the human health benefits shows the expected positive correlation between the population density and the health benefits obtained from the emission reduction scenarios. It means, therefore, that in densely populated areas the potential health benefits of the reduction scenarios are larger than in suburban/rural areas. Furthermore, these abatement measures are focused on the main activity sources, mostly concentrated in urban centres, and therefore air quality improvements in relation to the reference scenario are more significant in these air pollution hotspots. The largest contribution for health

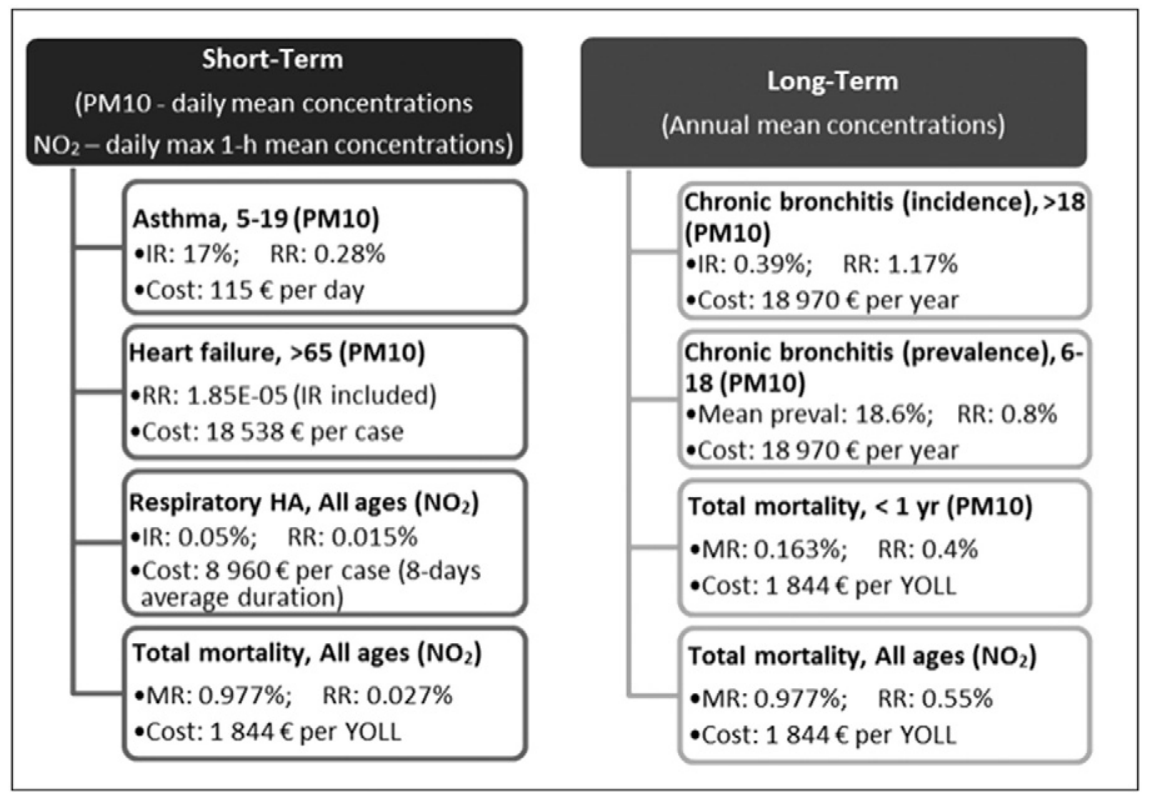

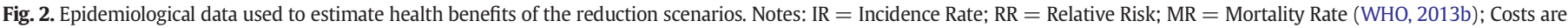

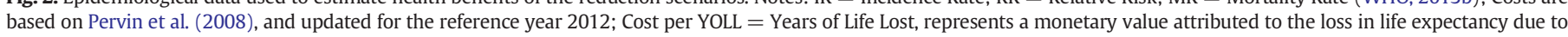
air pollution. 


\section{Reference}

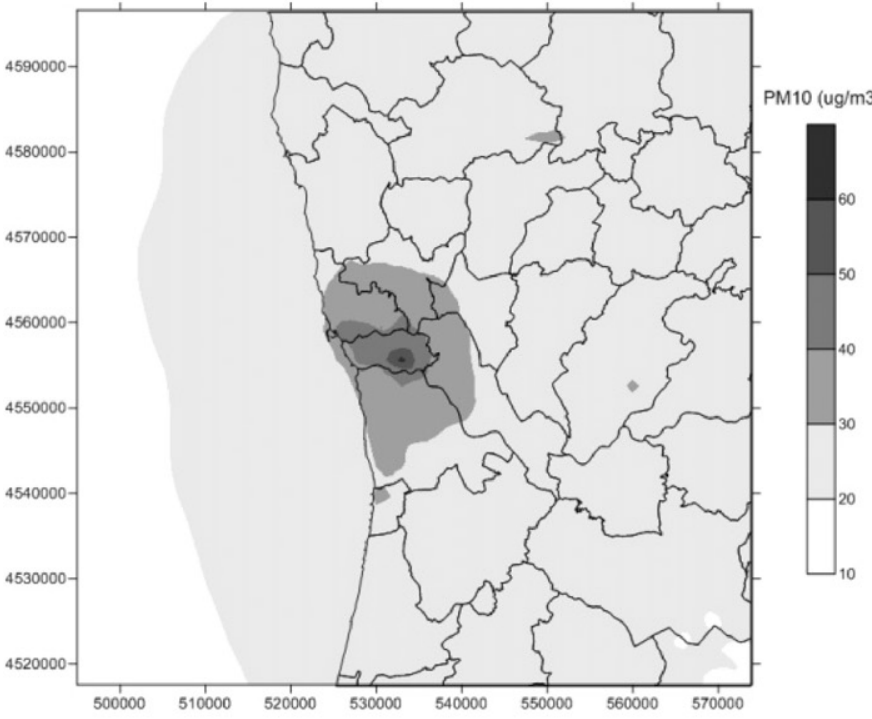

a
HYB+ FIR+LEZ+IND

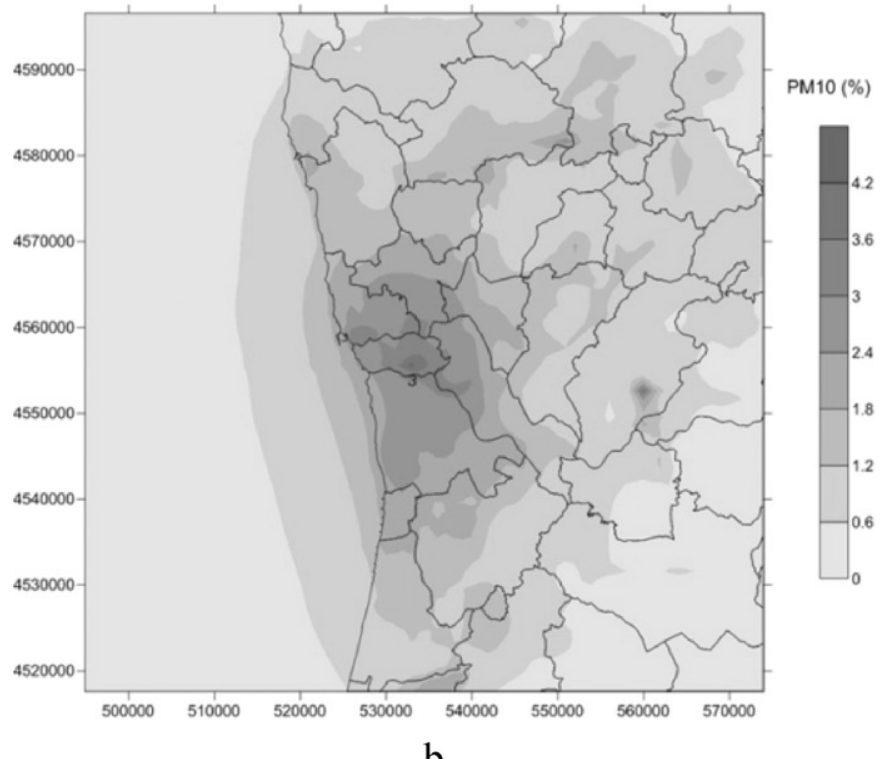

b

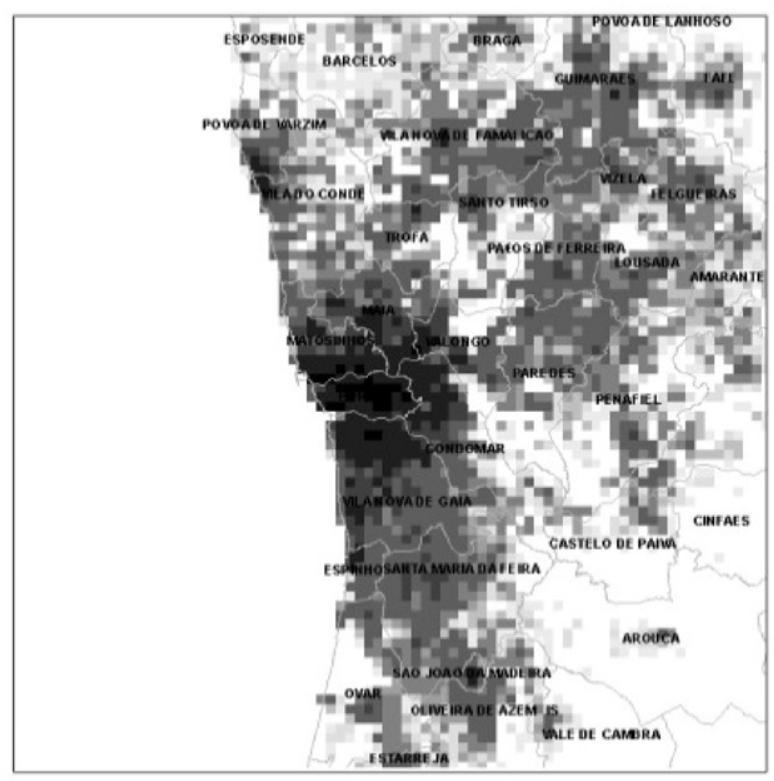

C

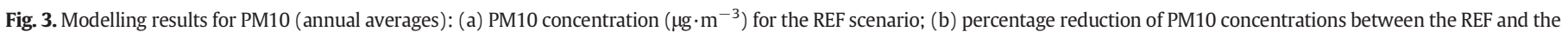
scenario including all the reduction measures; (c) human health benefits $\left(€ \cdot y^{-1}\right)$ for the total reduction scenario.

benefits derives from the reduction in PM10 concentrations in the Grande Porto municipalities, especially in Porto, Matosinhos, Maia and Vila Nova de Gaia. The exception is the LEZ scenario, whose effects are only felt in the influence area of the proposed LEZ.

Regarding the health benefits from reductions in NOx concentrations, these are much lower than those for PM10 and are only evident for the HYB and LEZ scenarios. Note that the fireplaces reconversion (FIR) is mostly focused on reducing PM10 levels, and it was assumed that the installation of industrial clean technologies (IND) would only affect PM10 emissions. Moreover, the NOx benefits are restricted to a few cells of the modelling domain, corresponding to the areas where HYB and LEZ measures are applied, although for LEZ the air quality improvement regarding $\mathrm{NO}_{2}$ is small (lower than $0.6 \%$ ).

As presented in Fig. 5, analysis of the average air quality improvement for PM10 and $\mathrm{NO}_{2}$ for the entire study domain versus total health benefits for the tested reduction scenarios, shows that these two variables are linearly correlated. This linearity occurs due to the arithmetic operation used to calculate the health impacts (Eq. (1)), keeping the exposed population and the impact functions as spatially constant elements to all scenarios.

Fig. 5 clearly shows which reduction scenarios mostly contribute to air quality improvement in the study domain. Comparing the health benefits provided by each pollutant, it is obvious that health benefits from PM10 air quality improvement are much higher (two orders of magnitude) than the ones related to $\mathrm{NO}_{2}$. In terms of individual measures application, the industry scenario (IND) is most effective to abate PM10 air pollution levels (average improvement of $0.61 \%$ ), while the Low Emission Zone scenario (LEZ) is least effective to reduce PM10 concentrations (almost no improvement due to restricted influence area) in the Grande Porto area. The hybrid vehicles measure (HYB) resulted to be most effective in improving $\mathrm{NO}_{2}$ air quality. The same is not verified for the IND scenario, as the measures considered/ 


\section{Reference}

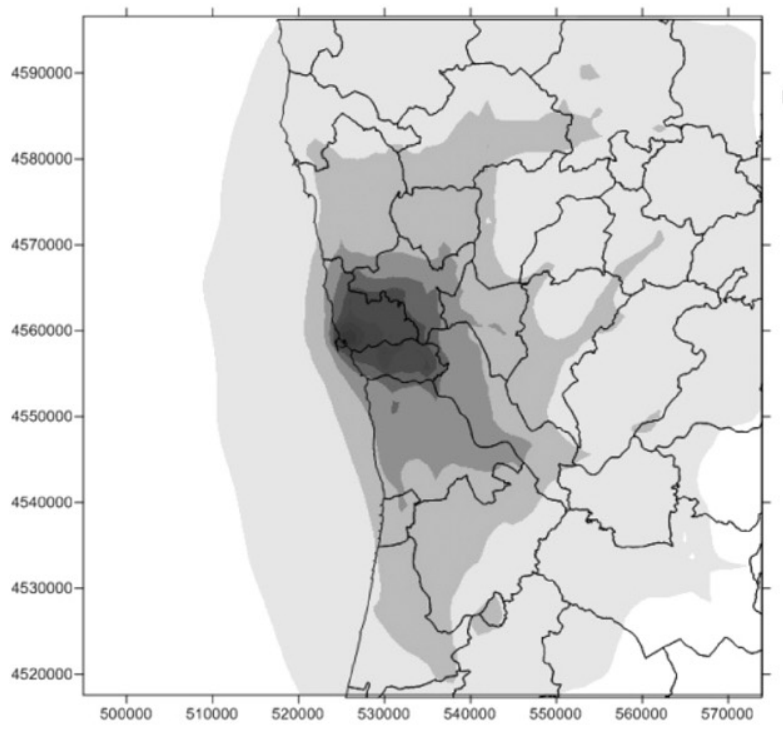

a

\section{HYB+ FIR+LEZ+IND}
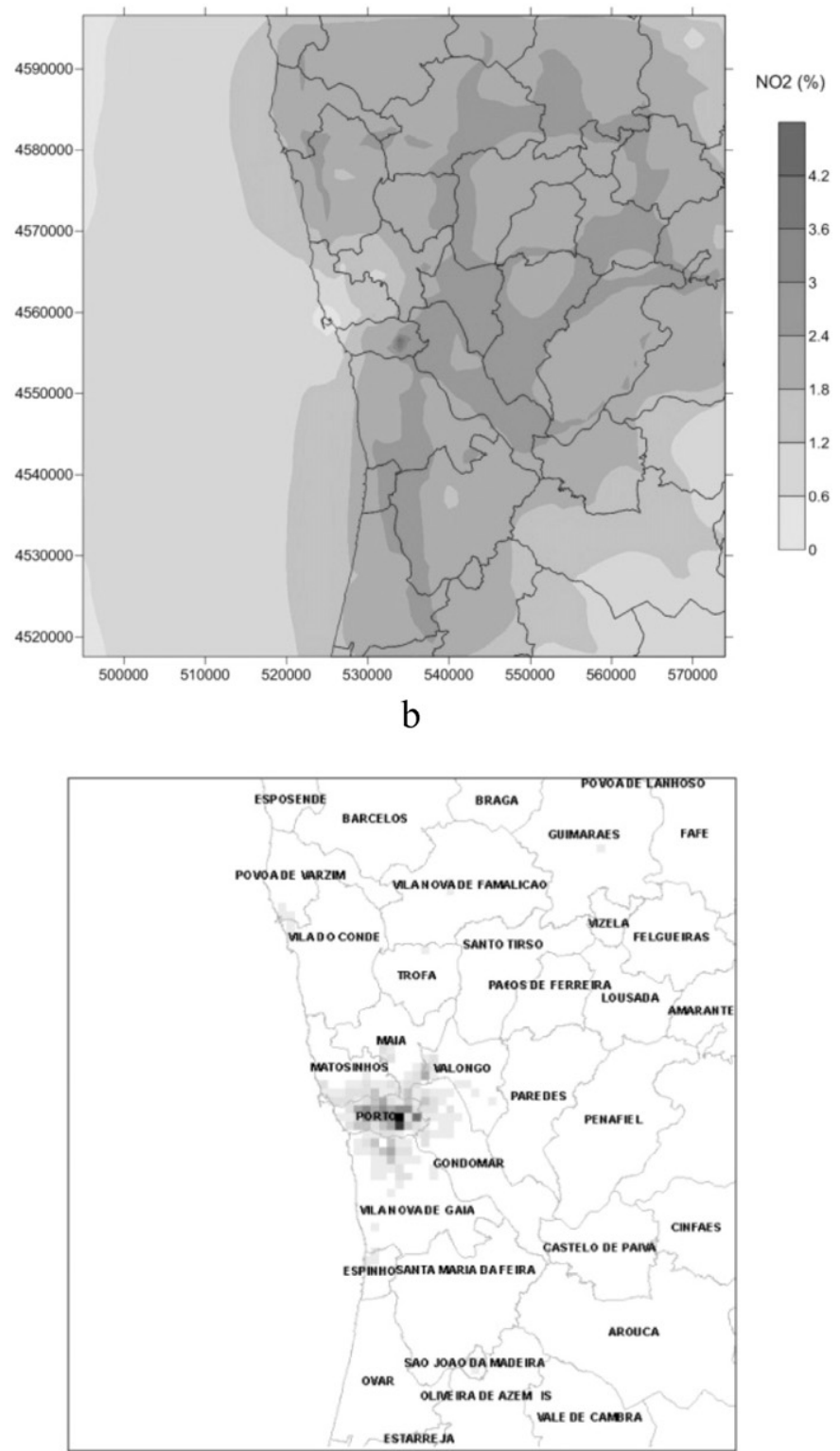

C

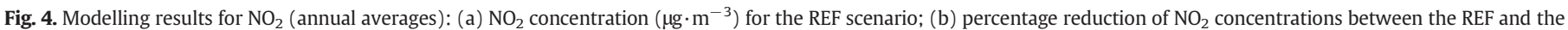
scenario including all the reduction measures; (c) human health benefits $\left(€ \cdot \mathrm{y}^{-1}\right)$ for the total reduction scenario.

included do not have impact on this pollutant. The reduction scenario combining all measures (HYB + FIR + LEZ + IND) leads to a reduction in PM10 air pollution of almost $1 \%(0.97 \%)$ and a reduction in $\mathrm{NO}_{2}$ of $1.8 \%$, corresponding to an expected health benefit of 8.9 million $€ /$ year, for which $\mathrm{NO}_{2}$ contributes with less than 90 thousand $€$.

\subsection{Cost-benefit assessment}

The application of the MAPLIA system was completed with a comparison of the internal/implementation costs and health benefits (or avoided external costs) associated with each scenario, taking as basis the year 2012. Table 1 summarizes the estimated values (in M€/year) of internal and external costs (benefits), for the most relevant reduction scenarios tested and considering the aggregate effect of PM10 and NOx pollutants.

The net benefit per reduction scenario corresponds to the difference between the total health benefits (for NOx and PM10 and considering both short and long-term effects) and the total implementation costs (in M€/year). Table 1 shows that the fireplaces' scenario (FIR) is probably the best strategic option to improve air quality and reduce negative health impacts, as this abatement measure provides largest net benefits (1.0 M€/year) with a benefit-cost ratio of 2.25. Furthermore, the significant impact of this scenario when combined with other measures is notable.

\section{Conclusions}

The traditional approach used in air quality management, particularly with respect to the adoption of measures to improve air quality, is not regularly based on the integrated assessment of the health and economic impacts of emissions abatement measures. Moreover, Air Quality Plans (AQP) rarely include a cost-benefit analysis, which is essential for decision-making. 

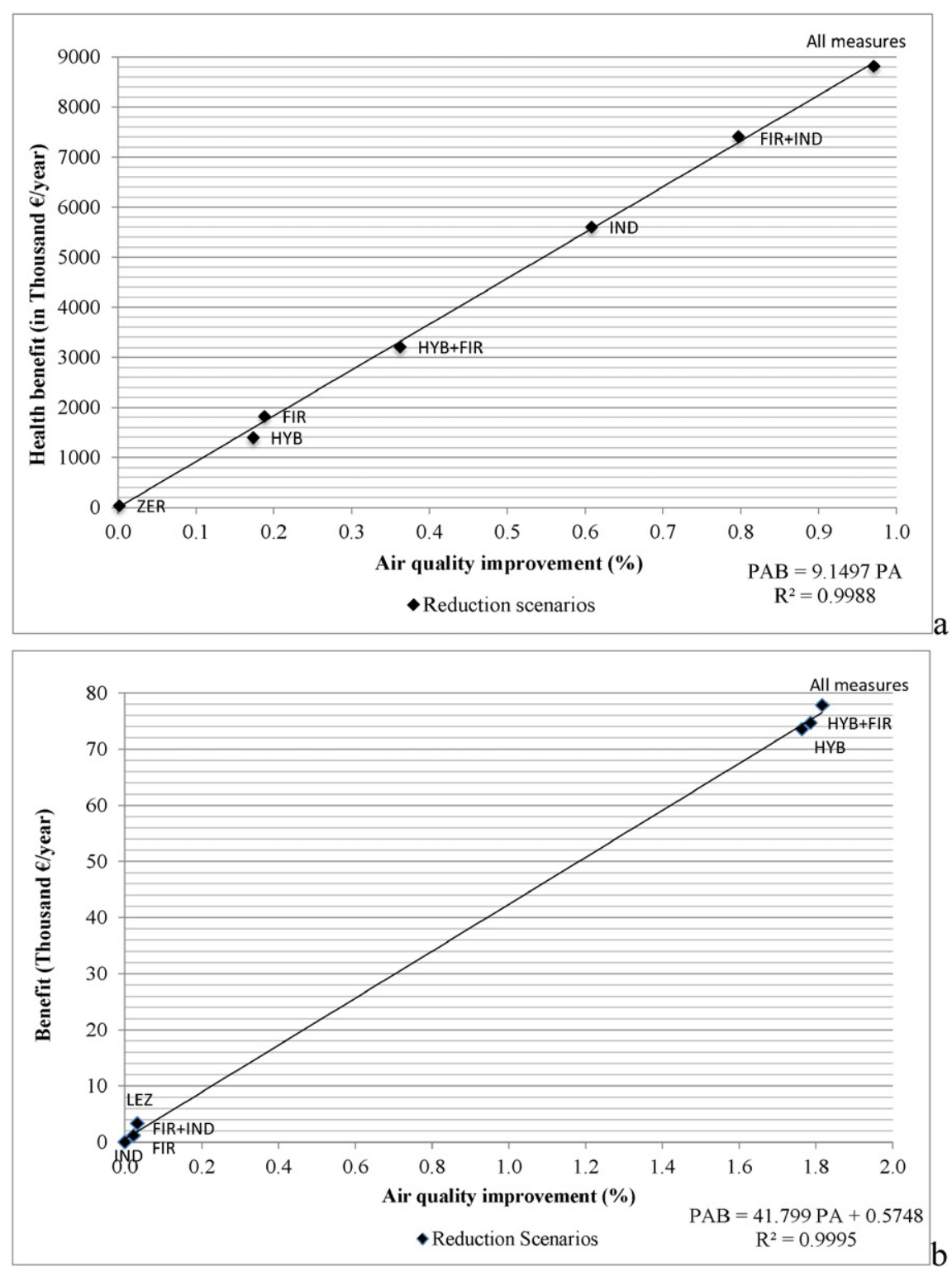

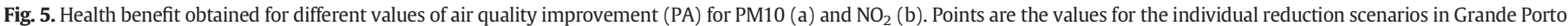
$(\mathrm{PA})$. The line corresponds to the benefit function (PAB).

This work aimed to overcome these limitations through the development and application of an integrated assessment system that addresses the full chain of cause-effects (from emissions through to impacts) for the evaluation of potential measures to include in an urban AQP. This approach not only includes the traditional steps of the evaluation of measures, such as the expected emissions reduction and resulting air quality improvement, but also considers the population exposure and health impacts, quantified in terms of morbidity and mortality as well as in terms of costs.
An IAM system specifically adapted to urban areas was developed (the MAPLIA system) following a scenario analysis approach and applied to a Portuguese urban region - the Grande Porto Area. A group of 15 emission reduction scenarios was defined based on combinations of the following 4 emission reduction measures: (i) replacing $10 \%$ of light vehicles below EURO 3 by hybrids; (ii) introducing a Low Emission Zone in the city of Porto banning vehicles below EURO 3; (iii) replacing/ reconverting $50 \%$ of open wood stoves; and (iv) application of particle reduction technologies allowing reducing 10\% of PM10 emissions from

Table 1

Cost-benefit analysis of the reduction scenarios.

\begin{tabular}{|c|c|c|c|c|}
\hline Reduction scenario & Implementation costs $\left(\mathrm{M} € \cdot \mathrm{y}^{-1}\right)$ & Health benefits $\left(\mathrm{M} € \cdot \mathrm{y}^{-1}\right)$ & Net benefit $\left(\mathrm{M} € \cdot \mathrm{y}^{-1}\right)$ & Benefit-cost ratio (BCR) \\
\hline HYB & 2.0 & 1.5 & -0.5 & 0.75 \\
\hline FIR & 0.8 & 1.8 & 1.0 & 2.25 \\
\hline LEZ & $3.8 \mathrm{E}-2$ & $3.9 \mathrm{E}-2$ & $1.0 \mathrm{E}-3$ & 1.03 \\
\hline IND & 5.8 & 5.6 & -0.2 & 0.97 \\
\hline $\mathrm{HYB}+\mathrm{FIR}$ & 2.8 & 3.3 & 0.5 & 1.18 \\
\hline FIR + IND & 6.5 & 7.4 & 0.9 & 1.14 \\
\hline $\mathrm{HYB}+\mathrm{FIR}+\mathrm{LEZ}+\mathrm{IND}$ & 8.6 & 8.9 & 0.3 & 1.03 \\
\hline
\end{tabular}


industrial combustion and production processes. All these scenarios were evaluated in terms of emissions, air quality, health and cost-benefit analysis. Results revealed that, among the 15 scenarios analysed, the resulting scenario including all 4 measures lead to a total net benefit of $0.3 \mathrm{M} € \cdot \mathrm{y}^{-1}$. The largest benefit is obtained for the scenario considering the conversion of $50 \%$ of open wood stoves into heat recovery wood stoves. Although the implementation costs of this measure are high, the benefits outweigh the costs. The most cost-efficient scenario is the one that combines the heat recovery wood stove measure and the replacement of $10 \%$ of passenger cars below EURO 3 by hybrid vehicles. Notwithstanding, the positive effect with regard to health is underestimated as there are other health indicators (beyond the analysed indicators) evidencing a close relationship with the air pollution. It should also be noted that a comprehensive cost-benefit analysis should also take into account the effects of air pollution to the environment, which were not considered in the present study and may lead to much higher net benefits.

It is not necessarily straightforward to compare results from costbenefit studies on air quality improvement, as scales of analysis, pollution sources, levels and types, considered measures and locations of implementation, climate, geographic and demographic conditions, and included cost and benefit categories vary widely across studies. Hence, cost-benefit indicator values vary widely across studies. For example, EPA (2011) estimates benefit-cost ratios of between 25 and 40 associated with meeting the US 1990 Clean Air Act Amendment, Pearce and Koundouri (2004) obtain benefit-cost ratios of between 1 and 18 associated with meeting the EU Registration, Evaluation and Authorisation of Chemicals (REACH) chemicals policy, and the AEA (2010) estimate benefit-cost ratios of between 12 and 37 (EU-27) and 44 and 144 (Portugal) associated with meeting the position outlined in the Thematic Strategy on Air Pollution (TSAP). Avoided external cost studies show that meeting the EU limit values of Directive 2008/50/EC (for $\mathrm{NO}_{2}$ and PM10) in Spain (Vedrenne et al., 2015) can provide benefits of up to $5.5 \mathrm{M} €$ by 2020 (with $40 \%$ of these due to health benefits), while the implementation of emission reduction measures (including $\mathrm{PM} 10, \mathrm{SO}_{2}$ and $\mathrm{O}_{3}$ ) in the wider Athens area (Mirasgedis et al., 2008) are estimated to provide benefits of up to $39 \mathrm{M} € \cdot \mathrm{y}^{-1}$ (with industrial sector benefits ranging between $0.1 \mathrm{k€} \cdot \mathrm{y}^{-1}$ and $\left.10 \mathrm{M} € \cdot \mathrm{y}^{-1}\right)$.

In summary, the MAPLIA system is an approach suited to support the policy decision, allowing better management of human, technical and financial resources, public and private, contributing to a greater acceptance and facilitated implementation by the agents involved, and towards improved air quality and better quality of life of citizens.

\section{Acknowledgments}

The authors acknowledge the financial support of FEDER through the COMPETE Programme and the national funds from FCT - Science and Technology Portuguese Foundation - within projects PEst-C/MAR/ LA0017/2013 and UID/AMB/50017/2013, for the MAPLIA Project (PTDC/AAG-MAA/4077/2012), the post doc grant of J. Ferreira (SFRH/ $\mathrm{BPD} / 100346 / 2014$ ), and the $\mathrm{PhD}$ grants of $\mathrm{H}$. Relvas (SFRH/BD/ 101660/2014), C. Gama (SFRH/BD/87468/2012) and C. Silveira (SFRH/ $\mathrm{BD} / 112343 / 2015)$.

\section{References}

AEA, 2010. Cost benefit analysis for the revision of the National Emission Ceilings Directive. Report AEA/ ED47788 Interim Issue 3 for the European Commission. UK, AEA Technology 26pp.

Amann, M., Bertok, I., Borken-kleefeld, J., Cofala, J., Heyes, C., Höglund-isaksson, L. Klimont, Z., Nguyen, B., Posch, M., Rafaj, P., Sandler, R., Schöpp, W., Wagner, F., Winiwarter, W., 2011. Cost-effective control of air quality and greenhouse gases in Europe: modeling and policy applications. Environ. Model Softw. 26 (12), 1489-1501.

APA (Portuguese Environmental Agency), 2014. Portuguese Informative Inventory Report 1990-2012. Submitted Under the UNECE Convention on Longrange Transboundary Air Pollution. Agência Portuguesa do Ambiente (Ed.), Amadora, Portugal, Março 2014.
APPRAISAL (Project on Air Pollution Policies foR Assessment of Integrated Strategies At regional and Local scales), 2013t. Summary Review of Air Quality and Health Assessment Methods, Report No. D2.7, Brescia (35 pages).

APPRAISAL (Project on Air Pollution Policies foR Assessment of Integrated Strategies At regional and Local scales), 2013t. Air Quality Assessment and Planning, Including Modelling and Measurement, Report No. D2.3, Brescia (49 pages).

Borrego, C., Monteiro, A., Sá, E., Carvalho, A., Coelho, D., Dias, D., Miranda, A.I., 2012b. Reducing NO2 pollution over urban areas: air quality modelling as a fundamental management tool. Water, Air and Soil Pollution 223, 5307-5320.

Borrego, C., Sá, E., Carvalho, A., Sousa, J., Miranda, A.I., 2012a. Plans and programmes to improve air quality over Portugal: a numerical modelling approach. Int. J. Environ. Pollut. 48, 60-68.

Borrego, C., Tchepel, O., Costa, A.M., Martins, H., Ferreira, J., Miranda, A.I., 2006. Traffic-related particulate air pollution exposure in urban areas. Atmos. Environ. 40, 7205-7214.

Borrego, C., Tchepel, O., Salmim, L., Amorim, J.H., Costa, A.M., Janko, J., 2004. Integrated modelling of road traffic emissions: application to Lisbon air quality management. Cybern. Syst. 35, 535-548.

Borrego, C., Valente, J., Carvalho, A., Sá, E., Lopes, M., Miranda, A.I., 2010. Contribution of residential wood combustion to PM10 levels in Portugal. Atmos. Environ. 44, 642-651.

Brook, R.D., Franklin, B., Cascio, W., Hong, Y., Howard, G., Lipsett, M., Luepker, R., Mittleman, M., Samet, J., Smith Jr., S.C., Tager, I., Expert Panel on Population and Prevention Science of the American Heart Association, 2004. Air pollution and cardiovascular disease: a statement for healthcare professionals from the Expert Panel on Population and Prevention Science of the American Heart Association. Circulation 109 (21), 2655-2671.

Carnevale, C., Finzi, G., Pisoni, E., Volta, M., Guariso, G., Gianfreda, R., Maffeis, G., Thunis, P., White, L., Triacchini, G., 2012. An integrated assessment tool to define effective air quality policies at regional scale. Environ. Model Softw. 38, 306-315.

CCDR-LVT (Lisbon Regional Coordination and Development Commission), 2006m. Plans and Programmes to Improve Air Quality in the Region of Lisbon and Tagus Valley, Lisbon (234 pages)

Comes, T., Doll, C., Fröhling, M., Hiete, M., Ilsen, R., Krail, M., 2010. Challenges for national clean air policy. Ökologisches Wirtschaften-Fachzeitschrift 25 (2).

Costa, S., Ferreira, J., Silveira, C., Costa, C., Lopes, D., Relvas, H., Borrego, C., Roebeling, P. Miranda, A.I., Teixeira, J.P., 2014. Integrating health on air quality assessment-review report on health risks of two major European outdoor air pollutants: $\mathrm{PM}$ and $\mathrm{NO}_{2}$. Journal of Toxicology and Environmental Health, Part B: Critical Reviews 17, 307-340.

Duque, L., Relvas, H., Silveira, C., Ferreira, J., Monteiro, A., Gama, C., Rafael, S., Borrego, C. Miranda, A.I., 2016. Evaluating strategies to reduce urban air pollution. Atmos. Environ. 127, 196-204. http://dx.doi.org/10.1016/j.atmosenv.2015.12.043.

EC (European Commission), 2005. ExternE Externalities of Energy - Methodology 2005 Update, Office for Official Publications of the European Communities, Peter Bickel and Rainer Friedrich, EUR 21951 EN.

EEA (European Environment Agency), 2015. Air Quality in Europe - 2015 Report, EEA Report. No.5/2015, Copenhagen ISSN 1977-8449, 64 pp.

EPA (US Environmental Protection Agency), 2011. The Benefits and Costs of the Clean Air Act from 1990 to 2020. Office of Air and Radiation, US. 35 pp

Gehring, U., Heinrich, J., Krämer, U., Grote, V., Hochadel, M., Sugiri, D., Kraft, M., Rauchfuss, K., Eberwein, H.G., Wichmann, H.E., 2006. Long-term exposure to ambient air pollution and cardiopulmonary mortality in women. Epidemiology 17, 545-551.

Gonçalves, C., Alves, C., Pio, C., 2012. Inventory of fine particulate organic compound emissions from residential wood combustion in Portugal. Atmos. Environ. 50, 297-306.

Hurley, P., Physick, W., Luhar, K., 2005. TAPM: a practical approach to prognostic meteorological and air pollution modelling. Environ. Model Softw. 20, 737-752.

INE (Instituto Nacional de Estatística), 2012. Alojamentos familiares de residência habitual $\left(\mathrm{N}^{\circ}{ }^{\circ}\right)$ por Localização geográfica (à data dos Censos 2011), Existência de sistema de aquecimento e fonte principal de energia utilizada para aquecimento. (Dataset reporting the number of homes by geographic location, with heating systems and respective fuel used).

INTARESE project (Integrated Assessment of Health Risks of Environmental Stressors in Europe), 2007f. D15 Health Effects Methodology - Protocol and Guidelines. (112 p) http://www.integrated-assessment.eu/sites/default/files/Exposure-response\% 20functions\%20protocol_0.pdf.

Karvosenoja, N., Kangas, L., Kupiainen, K., Kukkonen, J., Karppinen, A., Sofiev, P., 2010. Integrated modeling assessments of the population exposure in Finland to primary PM2.5 from traffic and domestic wood combustion on the resolutions of 1 and $10 \mathrm{~km}$. Air Quality, Atmosphere \& Health 4 (3), 179-188.

Loomis, D., Grosse, Y., Lauby-Secretan, B., El Ghissassi, F., Bouvard, V. Benbrahim-Tallaa, L. Guha, N., Baan, R., Mattock, H., Straif, K., On behalf of the International Agency for Research on Cancer Monograph Working Group, 2013. The carcinogenicity of outdoor air pollution. The Lancet Oncology 14 (13), 1262-1263.

Mediavilla-Sahagún, A., ApSimon, H.M., 2006. Urban scale integrated assessment for London: which emission reduction strategies are more effective in attaining prescribed PM10 air quality standards by 2005. Environ. Model Softw. 21 (4), 501-513.

Mensink, C., Colles, A. Janssen, L, Cornelis, J., 2003. Integrated air quality modelling for the assessment of air quality in streets against the council directives. Atmospheric Environment 37 (37), 5177-5184. http://dx.doi.org/10.1016/j.atmosenv.2003.07.014.

Miranda, A.I., Silveira, C., Ferreira, J., Monteiro, A., Lopes, D., Relvas, H., Borrego, C. Roebeling, P., 2015. Current air quality plans in Europe designed to support air quality management policies. Atmospheric Pollution Research 6, 434-443.

Mirasgedis, S., Hontou, V., Georgopoulou, E., Sarafidis, Y., Gakis, N., Lalas, D.P., Loukatos, A. Gargoulas, N., Mentzis, A., Economidis, D., Triantafilopoulos, T., Korizi, K., Mavrotas, G., 2008. Environmental damage costs from airborne pollution of industrial activities 
in the greater Athens, Greece area and the resulting benefits from the introduction of BAT. Environ. Impact Assess. Rev. 28, 39-56.

Monteiro, A., Miranda, A.I., Borrego, C., Vautard, R., 2007. Air quality assessment for Portugal. Sci. Total Environ. 373, 22-31. http://dx.doi.org/10.1016/j.scitotenv.2006.10. 014.

O'Connell, E., Hurley, F., 2009. A review of the strengths and weaknesses of quantitative methods used in health impact assessment. Public Health 123 (4), 306-310.

Pearce, D., Koundouri, P., 2004. Regulatory assessment for chemicals: a rapid appraisal cost-benefit approach. Environ. Sci. Pol. 7, 435-449.

Pervin, T., Gerdtham, U.-G., Lyttkens, C.H., 2008. Societal costs of air pollution-related health hazards: a review of methods and results. Cost Effectiveness and Resource Allocation 6 (19), 22.

Raaschou-Nielsen, O., Andersen, Z.J., Beelen, R., Samoli, E., Stafoggia, M., Weinmayr, G., et al., 2013. Air pollution and lung cancer incidence in 17 European cohorts: prospective analyses from the European Study of Cohorts for Air Pollution Effects (ESCAPE). Lancet Oncol 14, 813-822.

Smith, K.R., Corvalán, C.F., Kjellström, T., 1999. How much global ill health is attributable to environmental factors? Epidemiology 10 (5), 573-584.

Soret, A., Guevara, M., Baldasano, J.M., 2014. The potential impacts of electric vehicles on air quality in the urban areas of Barcelona and Madrid (Spain). Atmos. Environ. 99, $51-63$.

USEPA (United States Environmental Protection Agency), 2009. Cleaner Burning Wood Stoves and Fireplaces. (Available at:) http://www.epa.gov/woodstoves/basic.html.
Vedrenne, M., Borge, R., Lumbreras, J., Conlan, B., Encarnación Rodríguez, M., De Andrés, J.M., De la Paz, D., Pérez, J., Narros, A., 2015. An integrated assessment of two decades of air pollution policymaking in Spain: impacts, costs and improvements. Sci. Total Environ. 527, 351-361.

Vedrenne, M., Borge, R., Lumbreras, J., Rodríguez, M.E. 2014. Advancements in the design and validation of an air pollution integrated assessment model for Spain. Environ. Model Softw., 57(0), 177-191.

Vlachokostas, C. Achillas, C. Moussiopoulos, N., Hourdakis, E, Tsilingiridis, G. Ntziachristos, L., Banias, G., Stavrakakis, N., Sidiropoulos, C., 2009. Decision support system for the evaluation of urban air pollution control options: application for particulate pollution in Thessaloniki, Greece. Sci. Total Environ. 407, 5937-5938.

WHO - World Health Organization, 2013a. Health Effects of Particulate Matter: Policy Implications for Countries in Eastern Europe, Caucasus and Central Asia. WHO Regional Office for Europe, Geneva 20 pp.

WHO - World Health Organization, 2013b. Recommendations for Concentration-Response Functions for Cost-Benefit Analysis of Particulate Matter, Ozone and Nitrogen Dioxide, Health Risks of Air Pollution in Europe - HRAPIE Project, WHO Regional Office for Europe. Copenhagen, Denmark 54 pp.

Zachary, D.S., Drouet, L., Leopold, U., Reis, L.A., 2011. Trade-offs between energy cost and health impact in a regional coupled energy-air quality model: the LEAQ model. Environ. Res. Lett. 6 (2), 024021. 